\title{
APORTUL BISERICII ORTODOXE ÎN PROCESUL PRIVIND INCLUZIUNEA RELIGIOASĂ ȘI SOCIALĂ A ROMILOR DIN SPAT,IUL GEOGRAFIC ROMÂNESC
}

\author{
Marius CĂLDĂRARU*
}

\begin{abstract}
The contribution of the Orthodox Church during the religious and social inclusion process of the Gypsy people from the Romanian geographical space ${ }^{1}$. This study is necessary for a better understanding of religious and social inclusion of Gypsy people from Romania, by The Romanian Orthodox Church. The study completes the picture of historical events to which the Gypsies participated. In other words, the study is important because it shows us that the Church is not guilty for the Gypsy slavery in Moldova and Ungro Vlahia, although it does not infirm the research findings of previous historians, but it speaks us about some events which they have not considered important. We know about Saint Antim Ivireanu who took care of Gypsy people. We find out about his concern for the Gypsies from the indications that he gave to the monks of the monastery he founded. Also, the Patriarch Miron Cristea showed a lot of interest in bringing the Gypsies to the Church. The Patriarch was the godfather for one or more gypsy children and he delegated more gypsy missionaries. This missionary activity was continued, after the fall of Communism, by Archbishop Varsanufie, which founded in his diocese an office of catechesis the Gypsies and ordained gypsy priests for this mission. The Romanian Orthodox Church ordained gypsy priests immediately after the abolition of slavery, which took place in 1856, and this reality shows us that the Church purposed the religious and social inclusion of gypsies from Romania.
\end{abstract}

"PhD Student, Faculty of Orthodox Teology „Justinian Patriarch”, at University of Bucharest, Bucharest, Romania.

1 Studiu redactat sub îndrumarea Pr. Conf. Univ. Dr. Radu Petre Mureşan, care şi-a exprimat acordul pentru publicare. 
Keywords: gypsy, origin, pastoral, religious and social inclusion, gypsy priests.

\section{Introducere}

Cercetarea noastră are menirea de a contrazice părerea greșit conturată despre incluziunea religioasă și socială a romilor, privind o așazisă lipsă de reacție a Bisericii față de nevoile spirituale ale acestora, și întregește, fără a ascunde realitatea sclaviei și a atrocităților din Transnistria anului 1942, imaginea evenimentelor istorice românești la care au luat parte și romii. În cadrul studiului este succint abordată obârșia lor, sunt evidențiate primele atestări documentare ale romilor ${ }^{2}$ în teritoriile locuite de români și situația juridică a acestora. Folosind informațiile existente în publicaţia Glasul Romilor, în Apostolul și în unele documente, vom face cunoscută implicarea Bisericii în procesul emancipării minoritarilor romi, vom aduce informațiile necesare pentru a înţelege că Biserica Ortodoxă a fost preocupată de pastoraţia lor, că a existat un proiect pastoral, inițiat de Patriarhul Miron Cristea, care a ținut cont de ethosul acestora.

Vom încheia arătând că, prin câţiva ierarhi, după căderea sistemului comunist, Biserica Ortodoxă îşi regăseşte preocuparea pastoral misionară faţă de nevoiele spirituale ale romilor.

\section{Despre obârșie, primele atestări documentare în spațiul geografic românesc și primele hirotoniri de romi}

În stabilirea originii romilor au circulat două teorii: cea mai veche a susținut ideea originii egiptene; a doua părere, susţinută cu argumente lingvistice şi semantice de preotul Istvan Vali, la mijlocul sec. al XVIIIlea, probează ideea originii indiene, teză susţinută ulterior cu argumente extinse de istoricul german Grellmann³, dar şi de alţi 'ţiganologi', precum: Miklosich, Poissonier, Batllard, Ascoli, Kogălniceanu, Barbu

${ }^{2}$ Prefer scrierea fără dublarea consoanei r, întrucât nu împărtășesc convingerile celor mai mulți dintre romii intelectuali din România. Aceștia au atitudine anticlericală și sunt corecți din punct de vedere politic.

${ }^{3}$ Lucian CHERATĂ, Istoria Ţiganilor. Origine, specific, limbă, București, Edit. Z, 1994, p. 20. Cf. şi Gheorghe SARĂU, Rromii, India şi limba rromani, Bucureşti, Edit. Kriterion, 1998, p. $21,38-40$. 
Constantinescu şi alţii ${ }^{4}$. Acestora li s-au alăturat: A. Fraser ${ }^{5}$, D. M. Crowe $^{6}$, D. Nelson ${ }^{7}$, Y. Matras ${ }^{8}$ etc.

În spaţiul românesc, romii sunt pentru prima dată consemnaţi în Țara Românească în anul 1385, într-un act de donaţie întocmit de voievodul Dan I (1383-1386) Mănăstirii Tismana. Domnitorul adaugă alte bunuri materiale celor pe care părintele său - Radu I (1377-1383), le acordase Mănăstirii Tismana, între care și 40 de sălașe de țigani 9 .

În Moldova, romii sunt consemnați în anul 1428, când Alexandru cel Bun (1400-1432) dăruiește mănăstirii Bistrița țigani și tătari ${ }^{10}$, iar în Transilvania de un document din anul 1511, rezumat în slavonă al originalului latinesc emis de Mircea cel Bătrân (care a stăpânit Țara Făgăraşului între anii 1390-1406), şi în care se precizează că 17 țigani corturari sunt stăpâniți acum de boierul Costea, din Țara Făgărașului ${ }^{11}$.

Din cele evidențiate, desprindem ideea conform căreia în Moldova și Muntenia, situația fiind oarecum diferită în Transilvania ${ }^{12}$, romii au fost robi, realitate validată și de mitropolitul Antim Ivireanul. Acesta face

${ }^{4}$ Ibidem, p. 21.

${ }^{5}$ Angus FrASER, Ţiganii, originile, migraţia şi prezenţa lor în Europa, trad. Dan Șerban SAVA, Ed. a II-a, Bucureşti, Edit. Humanitas, 2008, p. 41.

${ }^{6}$ David M. CRowe, A History of the Gypsies of Eastern Europe and Russia, Second Edition, New York, Palgrave Macmillan, 2007, p. XVII.

${ }^{7}$ Dean NELSON, European Roma descended from Indian ,, untouchables”, genetic study shows, disponibil la https://www.telegraph.co.uk/news/worldnews/europe/9719058/EuropeanRoma-descended-from-Indian-untouchables-genetic-study-shows.HTML (accesat la 15.12.2018).

8 Yaron MATRAS, The Romani Gypsies, Massachusetts, The Belknap Press of Harvard University Press Cambridge, 2015, p. 83.

${ }^{9}$ Petre Petcuț, Rromii din România. Documente, Vol. I, Cluj-Napoca, Edit. Kriterion și Edit. Institutului Pentru Studierea Problemelor Minorităţilor Naţionale, 2009, p. 62-63.

${ }^{10}$ Mirel BĂNICĂ, Bafta, Devla şi Haramul. Studii despre cultura și religia romilor, București, Edit. Polirom, 2019, p. 68.

11 Gabriel SAla, Neamul Țiganilor gabori. Istorie, mentalități, tradiții, Cluj-Napoca, Edit. Dacia, 2007, p. 11.

${ }^{12}$ Cei mai mulți dintre romii transilvăneni s-au aflat sub protecția coroanei şi au avut o situație juridică diferită în raport cu cei care au trăit în celelalte două Principate. Vezi Viorel AcHIM, The Roma in Romanian History, trad. în engleză de Richard DAVIES, New York, Edit. Central European University Press, 2004, p. 42. Cf. şi Vasile IONESCU, Sclavia Rromilor. Legislația sclaviei în Țările Române, f. 1., Edit. Artes, 2012, p. 16. 
următoarea precizare: „Cercetarea pentru grija sufletelor să se facă și la țigani și la țigănci și la copiii lor ce vor avea. Osândă de nu-i vor cerceta la vreme. Sunt și ei botezați în numele Sfintei Troițe și sunt creștini ca și noi"'13. Cu alte cuvinte, romii din Țara Românească erau, la începutul sec. al XVIII-lea, botezați, iar Biserica le-a purtat de grijă.

Grija pe care Biserica a purtat-o acestora este mult mai clar vădită după înlăturarea sclaviei romilor (1856), când BOR s-a implicat în pastoraţia directă a acestora. Dimitrie Dan vorbește despre doi clerici romi bucovineni, unul care era în viață în anul 1892 și altul care murise în anul $1872^{14}$, informaţii care pot data hirotonia acestora la puţină vreme după anul 1856 .

\section{Patriarhul Miron Cristea și pastorația romilor}

Ziarul Glasul Romilor (1934-1941) certifică implicarea BOR şi a Patriarhului Miron Cristea în procesul despre care vorbim. Contrar afirmației istoricului rom Petre Petcuț ${ }^{15}$, noi considerăm că BOR nu este vinovată de existența instituţiei sclaviei, care, în pofida faptului că au existat în sânul ei reprezentanți care nu au urmat scopului ei, a vizat binele duhovnicesc și social al romilor, mai ales după anul 1856. Implicarea instituţională a BOR în integrarea romilor şi în împlinirea nevoilor sufleteşti ale acestora poate fi observată din presa vremii. Astfel, publicaţia Glasul Romilor (în continnuare GR) şi unele documente oficiale atestă această contribuție.

Prima Asociație, care a vizat și incluziunea religioasă a romilor români, a fost înființată de G. A. Lăzărescu. Aceasta, conform Notei informative a Direcției Generale de Poliție, din 7.10.1933, a fost pusă sub protecția Patriarhului ${ }^{16}$. Lăzărescu afirmă că Patriarhul și Consiliul

13 Sfântul Antim IVIREANUL, Invățătura pentru așezămintele cinstitei mănăstiri a Tuturor Sfinților, manuscrisul nr. 2014, f. 12 [în Biblioteca Academiei Române].

14 Dan Dimitrie, Țiganii din Bucovina, Cernăuți, Tipo - și Litografia concesionată Arch. Silvestru Morariu-Andrievici, 1892, p. 32.

15 Petre Petcuț, Romii: Sclavie și libertate. Constituirea și emanciparea unei noi categorii etnice și sociale la Nord de Dunăre 1370-1914, (ediție electronică), București, Edit. Centrul Naţional de Cultură al Rromilor, 2015, p. 36.

${ }^{16}$ Lucian NĂSTASĂ/Andrea VARGA (eds.), „Minorităţi Etnoculturale, Mărturii Documentare. Ţiganii din România (1919-1944)" în Lucian NĂSTASĂ (coord.), Cercetare realizată în 
Central Bisericesc îl consideră pe el misionar pentru romi ${ }^{17}$, fapt dovedit şi de corespondența pe care a purtat-o cu Arhiepiscopia Bucureștilor ${ }^{18}$. După demisia acestuia (1934), florarii Gh. Niculescu și Nicolae Niculescu au făcut demersurile necesare recunoașterii Asociației de către $\operatorname{Stat}^{19}$. Din Statutul Asociației, art. 51, aflăm că Patriarhul a fost ales în unanimitate ca președinte de onoare ${ }^{20}$. Între țintele Asociației, care au vizat educația romilor, binele duhovnicesc și pe cel material, a fost şi îndemnul la supunere față de rege și Biserică ${ }^{21}$.

În primului număr al publicației $G R$ este reprodusă o fotografie de grup în care sunt Patriarhul Miron, primarul Gh. Manolescu, prefectul D. Sfetescu, frații Niculescu și alţi clerici ai vremii, cum sunt protoiereul Vasilescu și protosinghelul Teofil Ionescu, responsabilul Asociației Misionare „Patriarhul Miron”22. În textul de sub fotografie, romii mulțumesc Patriarhului pentru prezența în mijlocul lor și consideră evenimentul unul istoric pentru neamul lor. Conform articolului, Patriarhul a fost unul dintre naşii celor 100 de romi nomazi ${ }^{23}$.

Debutul publicației ne descoperă că scopul înființării Uniunii Generale a Romilor din România a fost împletirea incluziunii religioase cu cea socială. Implicarea Patriarhului și a primarului Manolescu, care a promis că are să-i pună pe cei botezați în posesia unor loturi de pământ ${ }^{24}$, demonstrează această preocupare. De asemenea, acțiunile de caritate ale romilor (balurile organizate pentru strângerea de fonduri ${ }^{25}$, alimentele

cadrul proiectului „Documente privind politicile față de minorități”, finanțat de Fundația pentru o Societatea Deschisă, Vol. II, Cluj-Napoca, Edit. Centrului de Resurse pentru Diversitatea Etnoculturală, 2001, p. 107.

${ }^{17}$ Ibidem, p. 108.

18 ArhIVA ARHIEPISCOPIEI BuCUREȘTILOR, Dosar corespondență cu Uniunea Romilor, 1934.

${ }^{19}$ Arhivele Naționale (Serviciul Arhive Naționale Istorice Centrale), Sentința nr. 117/1934 dată de Tribunalul Ilfov. Secția I-a Civilă Corecțională.

${ }^{20}$ Lucian NĂSTASĂ/Andrea VARGA (eds.), „Minorități Etnoculturale, Mărturii Documentare. Țiganii din România (1919-1944)”, p. 147.

${ }^{21}$ SeCRETARIATUl GENERAL, „Apel către toți romii din țară”, în Glasul Romilor, 3/1937, p. 2.

22 T. DELACRAINICI, „Adunarea Generală a Frăției misionare ortodoxe Patriarhul Miron” în Cuvânt Bun, 13-14/1936, p. 1-4.

23 Uniunea Generală a ROMILOR din România, în Glasul Romilor, 1/1934, p. 1. Cf. și CRONICAR, „Botezul a o sută de romi la Ploiești”, în Apostolul, 20/1934, p. 355-356.

${ }^{24}$ REDACȚIA, în Glasul Romilor, 1/1934, p. 3.

${ }^{25}$ REDACȚIA, „Balul Asociației”, în Glasul Romilor, 12/1939, p. 4. 
dăruite ${ }^{26}$, ajutoarele distribuite de Crăciun ${ }^{27}$ și de Înviere, în curtea Bisericilor ${ }^{28}$ ) confirmă prezența activităților liturgice şi misionarpastorale.

Misionarii romi, conform ziarului $G R$, au respectat indicațiile statutare. Consecinţa acestei misiuni: 324 de copii botezați în Comuna Tinca (Bihor); în Turnu Severin au fost săvârșite 20 de botezuri și 50 de cununii. Slujbele au fost săvârșite de Episcopul Vartolomeu al Râmnicului; în Bărbulești au avut loc 100 de cununii, nașii au fost ministrul Aurelian Pentoiul cu soția și prefectul județului cu soția; în Timiș au fost cununate 50 de perechi, eveniment la care a luat parte Ministrul Educației Naționale C. Angelescu, fostul Ministru interimar al cultelor $^{29}$; în Satul Mare au avut loc 100 de cununii; tot în Turnu Severin au avut loc 45 de botezuri și 150 de cununii, iar nașii acestora au fost ministrul R. Franasovici și soția ${ }^{30}$; în Giurgiu au fost botezați 80 de romi, eveniment la care a participat și Patriarhul ${ }^{31}$. Thinând cont de rezultatele activității misionare, Redacţia $G R$ informa în 1940: „Nu a rămas cătun necercetat, nici un sălaș, în care copiii să nu fie creștinați și adaptați religiunii noastre ortodoxe" ${ }^{" 32}$.

Schimbările politice survenite în Europa în ajunul celui de-Al Doilea Război Mondial, alături de evenimente interne, cum sunt moartea patriarhului (1939), care a fost marcată cu multă reverenţă, respect şi recunoştinţă de către publicația romă $\breve{a}^{33}$, îlăturarea din scaun a regelui şi instaurarea regimului totalitarist (1940), au contribuit la schimbarea opiniei publice faţă de romi. Aceștia erau consideraţi needucaţi, răufăcători, că fac prea mulţi copii etc. Într-un articol publicat în $G R, G h$.

${ }^{26}$ P. DuMITRESCU, „Opera de ajutorare”, în Glasul Romilor, 12/1939, p. 4.

${ }^{27}$ Radu G. RADU, „Ajutoarele distribuite de Sfintele Paști și Crăciun, Familiilor și copiilor romi din Capitală, pe anul 1939”, în Glasul Romilor, 14/1940, p. 2.

28 V. Bulgaru, „Paștile copiilor săraci ai Asociației noastre”, în Glasul Romilor, 14/1940, p. 4.

${ }^{29}$ Pr. P. PARTENIE, „D-1 Ministru Dr. Angelescu și revendicările clerului”, în Viitorul, 10/1936, p. 2-3.

${ }^{30}$ INFORMAȚIUNI, „Serbarea de la Turnu Severin”, în Glasul Romilor, 7-8/1937, p. 4.

31 "Botezul romilor mahomedani și cununarea a 300 de perechi la Giurgiu", în Apostolul, 21/1935, p. 328-329.

32 ReDACȚiA, „Muncă, Pricepere și Gospodărie”, în Glasul Romilor, 14/1940, p. 1.

${ }^{33}$ Neacşu RADU, „I.P.S.S. Patriarhul Miron Cristea”, în Glasul Romilor, 12/1939, p. 2. 
Niculescu încearcă să îi liniștească pe cititorii care se simțeau amenințați de natalitatea crescândă a romilor, arătând că moartea infantilă diminuează creșterea numărului $\operatorname{lor}^{34}$. Poate că această opinie publică a determinat şi deportarea dictată de mareşalul Antonescu. În cadrul procesului său, acesta justifica deportarea acestora în Transnistria (1942) prin faptul că astfel au fost feriţi de mânia orăşenilor care, fiind terorizaţi de bande de țigani jefuitori și uneori ucigași, au cerut împușcarea lor $^{35}$.

Rămânând fidelă direcțiilor avute, publicaţia îşi încetează activitatea în anul 1941. În ultimul număr al ziarului găsim informații și despre numărul romilor din țară; acesta se situa la începutul anului 1941 la $700.000-800.000^{36}$.

\section{Pastorația romilor după înlăturarea comunismului (1989)}

După anul 1989, activitatea pastorală a BOR este o altă dovadă a preocupării Bisericii pentru binele romilor. $\mathrm{Cu}$ ocazia împlinirii a 153 de ani de la dezrobire, PS Varsanufie Prahoveanu l-a hirotonit pe romul Daniel Ganga (20 februarie 2009), ,primul preot de origine romă” în Arhiepiscopia Bucureștilor.

Deși Presfinţitul Varsanufie nu a fost primul care după evenimentele din anul 1989 a hirotonit preoți pentru comunitățile rome, a fost întâiul care a înființat un birou special, condus de preotul Daniel Ganga, cu scopul de a-i apropia pe romi de Biserică ${ }^{37}$. Odată ales în scaunul de arhiepiscop al Râmnicului $\left(2014^{38}\right)$, Presfinţitul a înființat şi aici un birou de catehizare și a iniţiat mai multe proiecte care au țintit incluziunea religioasă și socială a romilor ${ }^{39}$.

${ }^{34}$ G. NiCULESCU, „Rasismul și Romii”, în Glasul Romilor, 1/1941, p. 3.

${ }^{35}$ Procesul Mareșalului Antonescu - Documente, ediție prefațată și îngrijită de Marcel Dumitru CiURCĂ, București, Edit. Saeculum I.O. și Europa Nova, 1995, p. 176.

${ }^{36}$ REDACȚIA, „Din istoricul Romilor”, în Glasul Romilor, 1/1941, p. 4.

${ }^{37}$ ZIARE.com, Primul preot rom şi-a pus patrafirul şi îşi începe cariera în Ferentari, disponibil la http://www.ziare.com/stiri/frauda/primul-preot-rrom-si-a-pus-patrafirul-si-isi-incepecariera-in-ferentari-681874 (accesat la 27.04.2019).

38 Pr. Dorin Nifon IANCU, IPS Varsanufie, la un an de la intronizare, disponibil la http://ziarullumina.ro/ips-varsanufie-la-un-an-de-la-intronizare-102619.html (accesat la 3.03.2019).

39 BIROUL de CATEHIZARE a ROMILOR, disponibil la http://arhiepiscopiaramnicului.ro/biroulde-catehizare-rromilor/sfanta-liturghie-ortodoxa-limba-rromani (accesat la 3.03.2019). 
Arhiepiscopul Alba Iuliei, Andrei Andreicuţ, actualul Mitropolit al Clujului, Maramureșului și Sălajului, după o încercare semi-eşuată în anul $1996^{40}$, reuşeşte să hirotoneaască un preot pentru comunitatea romă din Sebeş-Alba în anul 2005, în persoana lui Alin Călin Matei. Cu ajutorul arhiepiscopiei a fost cumpărată o casă şi amenajată aici o capelă în care este săvârșită Sfânta Liturghie pentru comunitatea romă. Ideea unei Biserici a romilor în Sebeş este consolidată după hirotonirea celui de-al doilea preot aici, în persoana lui Vasile Frăţilă ${ }^{41}$.

Arătând reale şi insistente preocupări pentru incluziunea pastorală şi liturgică a romilor, după mutarea sa în scaunul de Mitropolit al Clujului, arhiepiscopul Andrei oferă comunității romilor din municipiul Turda biserica Sf. Ioan Botezătorul, pentru a împlini nevoile spirituale ale romilor din cartierul Turda-fabrici ${ }^{42}$. Așadar, Marin Trandafir Roz, care este primul preot rom din eparhia Clujului, are misiunea de a deservi comunitățile rome aflate în municipiile Turda și Câmpia Turzii. În plus, slujba, care a fost săvârșită în ziua de 8 aprilie, Ziua Internațională a Romilor, a fost bilingvă. $\mathrm{Cu}$ această ocazie, mitropolitul Andrei a săvârșit și un parastas pentru romii care au fost uciși în lagărele de concentrare naziste și în Transnistria ${ }^{43}$.

\section{Concluzii}

Biserica Ortodoxă Română a avut în vedere incluziunea religioasă şi, după înlăturarea sclaviei, pe cea socială a romilor din România.

${ }^{40}$ Deşi hirotonit de arhiepiscopul Andrei pentru comunitatea romilor din Sebeş - Alba, tânărul Mihai Ciurar nu a fos acceptat de aceştia, experiența nefericită făcându-l chiar să se distanţeze de etnia romă, schimbându-şi numele în Dumitrescu (cf. Condica hirotoniilor din Eparhia Alba Iulia, poziţia 205/1996).

${ }^{41}$ Informaţiile cu privire la inţiativele arhiepiscopului Andrei Andreicuţ în Eparhia Alba ne-au fost furnizate de către pr. Dumitru A. Vanca, secretar eparhial în acea perioadă.

42 IPS Andrei a fost preotul acestei Biserici în perioada 1978-1985, el a cunoscut destul de bine comunitatea romă de aici. De asemenea, Arhiepiscopia are în derulare 50 de proiecte și programe sociale pentru romi. Vezi Anghel GHEORGHE, Mitropolitul Andrei a oficiat Sfânta Liturghie în limbile română şi romani pentru comunitatea din Turda-Fabrici, disponibil la https://basilica.ro/mitropolitul-andrei-a-oficiat-sfanta-liturghie-in-limbile-romana-siromani-pentru-comunitatea-din-turda-fabrici/ (accesat la 16.04.2019).

${ }^{43}$ COTIDIANUl, Premieră: Slujbă în limbile română și romani, oficiată de Mitropolit, disponibil la https://www.cotidianul.ro/premiera-slujba-in-limbile-romana-si-romani-oficiata-demitropolit/ (accesat la 16.04.2019). 
Exemplele aduse ne certifică afirmația, însă nădăjduim să putem ajunge și la alte informații similare, de folos pentru a extinde cercetările noastre în vederea unei analize pertinente a perioadei începuturilor (1385-1856), dar mai ales a celei contemporane.

Sclavia rămâne un fenomen social şi istoric, un accident moral nefiresc al manifestării umane, care încă există sub alte forme. În pofida faptului că au fost puțini clerici care și-au arătat public nemulțumirea față de această nefirească stare socială, unul dintre aceștia fiind arhimandritul Eufrosin Poteca, au existat și există reprezentanți ai Bisericii care au fost preocupați de binele duhovnicesc și social al romilor. Astfel, grija exprimată de Sfântul Mitropolit Antim Ivireanul a fost concretizată la jumătatea secolului al XIX-lea prin hirotonirea unor preoţi de etnie romă, iar în anii '30 acţiunile concrete şi pragmatice iniţiate şi susţinute de patriarhul Miron Cristea au fost dătătoare de speranţă. Stagnând în perioada sistemului comunist, misiunea Bisericii Ortodoxe printre romi, care este dătătoare de speranță, a fost reluată prin grija şi la iniţiativa unor ierarhi cum sunt Varsanufie şi Andreicuţ.

\section{Referinţe bibliografice:}

1. ACHIM, Viorel, The Roma in Romanian History, trad. în engleză de Richard Davies, New York, Edit. Central European University Press, 2004;

2. ANGHEL, Gheorghe, Mitropolitul Andrei a oficiat Sfânta Liturghie în limbile română și romani pentru comunitatea din Turda-Fabrici, disponibil la https://basilica.ro/mitropolitul-andrei-a-oficiat-sfantaliturghie-in-limbile-romana-si-romani-pentru-comunitatea-dinturda-fabrici/ (accesat la 16.04.2019);

3. ARHIEPISCOPIA RÂMNICULUI, BIROUL de CATEHIZARE a RoMILOR, disponibil la http://arhiepiscopiaramnicului.ro/biroul-de-catehizarerromilor-0 (accesat la 3.03.2019);

4. ARHIVA ARHIEPISCOPIEI BUCUREȘTILOR, Dosar corespondență cu Uniunea Romilor, 1934;

5. ARHIVEle NAȚIONALE (Serviciul Arhive Naționale Istorice Centrale) Sentința nr. 117/1934 dată de Tribunalul Ilfov. Secția I-a Civilă Corecțională;

6. BĂNICĂ, Mirel, Bafta, Devla şi Haramul. Studii despre cultura şi religia romilor, București, Edit. Polirom, 2019; 
7. Cherată, Lucian, Istoria Tiganilor. Origine, specific, limbăa, București, Edit. Z, 1994;

8. Colecţia periodicului Glasul Romilor (1934-1941);

9. COTIDIANUL, Premieră: Slujbă în limbile română și romani, oficiată de Mitropolit, disponibil la https://www.cotidianul.ro/premieraslujba-in-limbile-romana-si-romani-oficiata-de-mitropolit/ (accesat la 16.04.2019);

10. CRONICAR, „Botezul a o sută de romi la Ploiești”, în Apostolul, 20/1934, p. 355-356;

11. CRONICAR, „Botezul romilor mahomedani și cununarea a 300 de perechi la Giurgiu", în Apostolul, 21/1935, p. 328-329;

12. Crowe, M. David, A History of the Gypsies of Eastern Europe and Russia, Second Edition, New York, Palgrave Macmillan, 2007;

13. NELSON, Dean, European Roma descended from Indian „,untouchables”, disponibil la https://www.telegraph.co.uk/news/ worldnews/europe/9719058/European-Roma-descended-from-Indianuntouchables-genetic-study-shows.HTML (accesat la 15.03.2018);

14. DelacRAINICI, T., „Adunarea Generală a Frăției misionare ortodoxe Patriarhul Miron", în Cuvânt Bun, 13-14/1936, p. 1-4;

15. DAN, Dimitrie, Țiganii din Bucovina, Cernăuți, Tipo - și Litografia concesionată Arch. Silvestru Morariu-Andrievici, 1892;

16. IANCU, Dorin Nifon, IPS Varsanufie, la un an de la intronizare, disponibil la http://ziarullumina.ro/ips-varsanufie-la-un-an-de-laintronizare-102619.html (accesat la 3.03.2019);

17. FRASER, Angus, Tiganii, originile, migraţia şi prezenţa lor în Europa, Ed. a II-a, Bucureşti, Edit. Humanitas, 2008;

18. IONESCU, Vasile, Sclavia Rromilor. Legislația sclaviei în Țările Române, f. 1., Edit. Artes, 2012;

19. MATRAS, Yaron, The Romani Gypsies, Massachusetts, The Belknap Press of Harvard University Press Cambridge, 2015;

20. NĂSTASĂ, Lucian/VARGA, Andrea (eds.), „Minorități Etnoculturale, Mărturii Documentare. Țiganii din România (1919-1944)", în Lucian Năstasă (coord.) Cercetare realizată în cadrul proiectului „Documente privind politicile față de minorități”, finanțat de Fundația pentru o Societatea Deschisă, Vol. II, Cluj-Napoca, Edit. Centrului de Resurse pentru Diversitatea Etnoculturală, 2001;

21. PARTENIE, P., „D-1 Ministru Dr. Angelescu și revendicările clerului”, în Viitorul, 10/1936, p. 2-3;

22. Petcuț, Petre, Romii: Sclavie și libertate. Constituirea şi emanciparea unei noi categorii etnice și sociale la Nord de Dunăre 
1370-1914 (ediție electronică), București, Edit. Centrul Național de Cultură al Rromilor, 2015;

23. Petcuț, Petre, Rromii din România. Documente, Vol. I, ClujNapoca, Edit. Kriterion şi Edit. Institutului Pentru Studierea Problemelor Minorităților Naționale, 2009, p. 62-63;

24. Procesul Mareșalului Antonescu - Documente, ediție prefaţată și îngrijită de Marcel Dumitru CIURCĂ, București, Edit. Saeculum I.O. şi Europa Nova, 1995;

25. SALA, Gabriel, Neamul Țiganilor gabori. Istorie, mentalități, tradiții, Cluj-Napoca, Edit. Dacia, 2007;

26. SARĂU, Gheorghe, Rromii, India şi limba rromani, Bucureşti, Edit. Kriterion, 1998;

27. Sfântul ANTIM IVIREANUL, Invățătura pentru așezămintele cinstitei mănăstiri a Tuturor Sfinților, manuscrisul nr. 2014, f. 12 [în Biblioteca Academiei Române];

28. ZIARE.com, Primul preot rom şi-a pus patrafirul şi îş̧i începe cariera in Ferentari, disponibil la http://www.ziare.com/stiri/frauda/primulpreot-rrom-si-a-pus-patrafirul-si-isi-incepe-cariera-in-ferentari681874 (accesat la 27.04.2019). 